\title{
A PALAVRA DE IMPOSSÍVEL REPOUSO: PASOLINI E O OLHO-CÂMARA DE MURILO MENDES
}

\author{
Bárbara Piñeiro Pessôa \\ Universidade Federal Fluminense
}

\begin{abstract}
Resumo: Mais que uma teoria sobre o cinema, o cineasta Pier Paolo Pasolini nos deixou uma teoria sobre a linguagem e sua relação com o real. O cinema aparece como o disparador de uma pesquisa filosófica sobre as possibilidades da linguagem verbal em sua encruzilhada entre o conceitual e o material, entre sua historicidade e a utópica ânsia poética do alvorecer de um novo sentido ou, mais além, o trabalho com a impossibilidade do sentido. Ao estabelecer laços de diálogo entre a teoria do cinema de Pasolini e a poética de Murilo Mendes, pretendemos pensar aqui sobre a exigência poética do despojamento dos sentidos e o tratamento de corte e subtração conceitual dirigidos à palavra. A proposta de Pasolini teoriza sobre o cinema, mas é, sobretudo, uma teoria da linguagem, um confronto entre as possibilidades da literatura e do cinema. Nesta perspectiva, sua teoria nos ajuda a lançar um outro olhar ao trabalho poético de Murilo Mendes, interessado na palavra ativada por um olho-câmera, um olho capaz de descamar o real e a materialidade da palavra, num processo de subtração que ambiciona o permanente deslocamento de sentido, a palavra de impossível repouso.
\end{abstract}

Palavras-chave: Murilo Mendes. Pier Paolo Pasolini. Cinema. Colagem.

"O olho dispara a câmera lenta, a câmera veloz" Murilo Mendes, The Responsive eye

Subtrair da linguagem verbal o que faz dela ela mesma, num ato de visão e som. As imagens de Murilo acumulam-se e não cansam de proliferar-se. Outras vezes, as palavras se contaminam, num puxa-puxa fonético, que as autonomiza do sentido. O que faz de um olho um olho câmera? O que faz de uma escritura pura revelia musical?

Para Pasolini o próprio da linguagem do cinema é lançar mão de imagens, que ao contrário da linguagem verbal, não figurariam em um dicionário, ainda que sejam patrimônio comum. Tal a-gramaticalidade lhe daria ao cinema seu "tipo irracionalista: eis o que explica a qualidade onírica profunda do cinema e também a sua absoluta e imprescindível concreção, 
digamos, objetal”. (PASOLINI, 1982, p. 138).

O pensamento contrastivo de Pasolini entre literatura e cinema nos indica que a operação do escritor consiste em "tomar desse dicionário as palavras - como se fossem objetos guardados numa arca - e fazer delas um uso particular; particular no que respeita ao momento histórico da palavra e ao seu próprio momento. Deste modo, obtém um aumento de historicidade da palavra, isto é um aumento de significado" (PASOLINI, 1982, p. 139). Por outro lado,

$\mathrm{O}$ autor de cinema não possui um dicionário, mas uma possibilidade infinita. Por isso, a operação do autor de cinema não é uma, mas dupla. De facto: 1) ele tem que retirar do caos o im-signo, torná-lo possível e pressupô-lo como sistematizado num dicionário de im-signo significativos; 2) tem que realizar depois a operação do escritor; isto é, acrescentar a tal ou tal im-signo puramente morfológico a qualidade expressiva individual (idem).

Se a condenação da linguagem estaria na sua própria historicidade, a "salvação", por sua vez, do cinema, seria sua qualidade virginal, o fato de que sua linguagem de ação se presta a qualquer significado e este, por sua vez, é de manejo do autor, entendida por Pasolini como sua expressão individual. Na contramão desta diferença, mas servindo-nos de seus parâmetros, observamos que aqui não se trata de pensar em termos de uma historicidade ampliada, mas sim de um impulso de a-historicidade, a aurora de uma palavra que ao nascer, já pode morrer, cumprindo um destino de estrela cadente, destino efêmero, que lhe aparenta a fulguração, própria da imagem. A escrita relâmpago, escrita em perseguição de algo que a linguagem se esforça por alcançar, num ato de implosão, leva a marca de sua morte no momento mesmo de seu nascimento. Entretanto, este desejo permanece enquanto utopia, já que o próprio trabalho do poeta consiste em travar com a historicidade da palavra seu jogo.

Ainda assim, o pensamento de Pasolini nos ajuda a aproximar-nos deste olho câmera, que, desde já, mostra-se como um olho subtrativo, que lida com a palavra tirando dela o que a faz dicionarizável, pertencente a uma convenção. Subtrair o que há de convencional na palavra significa violar seu sentido, no quase extravio ou no desvio. No extravio, a materialidade da palavra se entrega à musicalidade, aproximando-se da glossolalia. No desvio, trata-se de criar imagens sempre recém-nascidas, na tentativa de livrar a linguagem verbal do peso de sua história.

Para entendermos este segundo movimento podemos identificar estes dois momentos do autor de cinema no trabalho de um olho câmera: Murilo corta da realidade seus objetos; Murilo os desvia de seu uso habitual e, partindo de sua materialidade, dá livre curso à 
memória ou à criação de conceitos abstratos. Mas, o que corta Murilo? Ou, como nos pergunta Pasolini ao indagar-se sobre o que chama de cinelíngua, "Que pesca, na realidade, a gramática da cinelíngua?" (PASOLINI, 1982, p. 169). Pasolini propõe que a gramática da cinelíngua "Pesca as suas unidades minimais, as unidades da segunda articulação: os objetos, as formas, os actos da realidade, a que chamamos cinema" (idem).

Da mesma forma, Murilo se fascina pelo poder caçador de sua visão: "O olho pesca" (MENDES, 1995, p. 988) o que o "invísivel adverte” (MENDES, ibidem, p. 1016). A imagem de um olho que pesca situa o olhar na travessia da transparência aquática. Aqui fica exposto não só sua qualidade de perseguidor, mas também a de transeunte dentro de uma materialidade. A pesca implica o ato da passagem através da qual se pode aceder ao invisível.

O olho-câmera trava com a linguagem que detém, a verbal, um combate particular. $\mathrm{O}$ olho dispara no intuito de fixação da realidade, Murilo afirma em letras garrafais: “A IDÉIA DE TENTAR FIXAR QUALQUER COISA ME IMPELE, ME FASCINA, ME ESPAVENTA” (MENDES, 1995, p. 1020). Se a idéia de fixação poderia aproximar-nos de uma estética fotográfica, posto que é através dela que o instante se petrifica, por outro lado, é pela rotação, pelo movimento dos fragmentos, que tais partes se aproximam do cinematográfico.

A linha vertical que Pasolini traça para a língua do cinema, uma língua que "mergulha no Significando" (PASOLINI, 1982, p. 138), deixa claro o aspecto de submersão na realidade. A mesma do olho vertical que Murilo identifica como revelador de uma realidade a ser descortinada:

\author{
O pintor de olho vertical \\ Olha fixamente para o muro \\ Descobre pouco a pouco \\ Uma perna um braço um tronco \\ A cara de uma mulher \\ Uma floresta um peixe uma cidade \\ Uma constelação um navio \\ (MENDES, 1995, p. 143).
}

O caráter vertical se liga indissoluvelmente ao aspecto escatológico do olhar. Para Pasolini,

Do grande poema de acção de Lenine à pequena página de prosa de acção de um empregado da Fiat ou de qualquer ministério, a vida está indubitavelmente a afastarse dos ideais humanistas clássicos e a perder-se na pragma. O cinematógrafo (com as outras técnicas audiovisuais) parece ser a língua escrita desta pragma. Mas talvez seja também a sua salvação, precisamente, porque a expressa - e a expressa a partir de dentro: produzindo-se dela e reproduzindo-a (PASOLINI, 1982, p. 145). 
A salvação pelo materialismo, que entende o dever vertical de "transfiguração do concreto" (MENDES, 1995, p. 123), pertencente à poesia, aparece repetidamente no poeta mineiro que afirma que "Quis filmar o milagre" (MENDES, ibidem, p. 124). O concreto da "Microlição das coisas", seção de textos de Poliedro (1972), nos mostra o olhar à mesa, à gravata, ao lençol, ao copo, ao tomate, à laranja, apontando a esta materialidade da visualidade em busca do "invisível que se esconde atrás do visível”, idéia que se cristaliza em um aforismo do "Texto Délfico".

O princípio mesmo da colagem aponta a esta tentativa de inserção do cotidiano no espaço da arte, criticando, assim, na perspectiva vanguardista, este mesmo espaço como lugar institucional separado da vida. Assim como as colagens surrealistas de Ernst, em que um dos procedimentos consiste em recuperar elementos da vida comum - textos de jornais, revistas ou propagandas - e colocá-los na tela, Murilo lança sua atenção aos objetos da vida vulgar. Se na colagem plástica o artista desvia tais elementos de seus contextos tradicionais para submetêlos a novos, colando no espaço da tela materiais considerados fora do terreno da arte, o escritor toma aqui estes elementos cotidianos também no sentido mostrá-los através de uma outra significação. Pelo deslocamento se esvazia o sentido utilitário das coisas e, em seu lugar, abre-se um outro, o poético. O olho recorta da realidade cotidiana o objeto, já não mais em sua função utilitária, mas num nível de percepção que o excede e transborda. Mas aqui, mais do que isso, é a própria palavra que é desalojada de seu sentido comum:

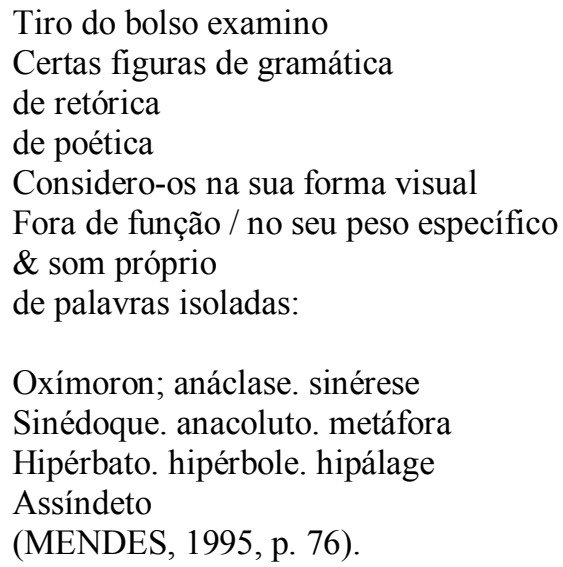

Essa lógica de subtração funcional anseia a forma do visível e do musical. Palavras imagens, palavras sons. A colagem em Murilo Mendes funciona tanto como uma acumulação de imagens, uma fulguração visual, como é ela que permite uma "destruição musical" da palavra, na exploração de novos ritmos e sons: “Além do além além do paralém alô a dupla 
flecha alada voa além do álamo, da lâmpada, além de Alá, além de Elêusis" (MENDES, 1995, p. 1048). O visual, por sua vez, é instigado pela atenção para as formas e cores das coisas, numa constante geometrização do espaço: "A cabra circular, tóteme/ A luz de leite. Um grande copo d'água./ Maria Callas: A túnica vermelha de Clitenestra apertada com tenazes" (idem).

Os fragmentos do oráculo délfico surgem e desaparecem com a mesma facilidade, como lampejos de seu visionarismo. A idéia de "supressão das passagens intermediárias" (MENDES apud MOURA, 1995, p. 31) e de corte configuram uma estética que anseia afetar a percepção do tempo e do espaço, assim como a linguagem cinematográfica o faz. Esta percepção é afetada pela câmera lenta do olhar, a qual a linguagem acede pelo silêncio, pela suspensão do tempo que o branco da página indica ou pela câmera veloz, pela fragmentação dos aforismas, a fragmentação que corta o continumm da linguagem, na dinâmica do disparo: "Procedi muitas vezes como um cineasta, colocando a "câmera" ora em primeiro plano, ora em segundo ou terceiro plano; planos estes representados pelo encontro ou o isolamento de palavras - sua valorização ou afastamento no espaço do poema" (idem). A idéia de um Poliedro, título do livro no qual se encontram "Microlição das coisas" e "Texto Délfico", aponta para este caráter multifacetado da linguagem, que se constitui de diferentes planos.

O poeta supervê a realidade e realiza, tal como o cinema para Artaud, uma vertigem imagética. Em "Brujería y cine", Artaud afirma que há toda uma vida oculta, vertiginosa, que a potência virtual do cinema pode acessar justamente pela sua qualidade de "embriaguez física que la rotación de imágenes comunica directamente al cerebro (...). El cine simple, tomado tal cual es, en lo abstracto, desvela un poco de esa atmósfera de trance, eminentemente favorable a ciertas revelaciones" (ARTAUD, 1973, p. 14). Artaud nos ajuda, assim, a identificar uma outra possível característica de um olho câmera: um olho vertiginoso, que dispara imagens. A embriaguez causada pela imagem mostra como esta linguagem imagética se constitui como refúgio do irracional, lugar de resistência do conceitual, e a verdadeira energia da revolução pela linguagem, como apontou Benjamin em seu ensaio sobre o surrealismo. "Em sua qualidade onírica" (idem), que não se divorcia do mundo das coisas, Pasolini se aproxima do pensamento de Artaud sobre o cinema. A imediaticidade desta linguagem que pode "con su materia directa, sin interposiciones, ni representaciones" (idem) assegurar-nos uma recepção eficaz e imediata da realidade, parece responder instantaneamente a uma vida oculta, essa vida que há que descobrir. Particularmente em "Setor Texto Délfico", Murilo se alinha a esta perspectiva que liga embriaguez, visionarismo 
e magia, uma vez que se utiliza da fragmentação e da profusão de imagens e sons para criação de uma linguagem que anseia a decifração do enigma através das palavras praticando, nas palavras de Merquior, um "messianismo do verbo" (MERQUIOR, 1996, p. 244): "Todas as palavras juntando-se formarão um dia uma coluna altíssima tocante as nuvens e decifrarão o enigma” (MENDES, 1995, p. 1045).

O "Setor Texto Délfico" se constitui de uma série de enigmáticos aforismas de tom oracular. Estas divisões obedecem a uma certa ordem construtiva que divide e dá uma configuração ao texto. Entretanto, a organização empregada está longe de ser de cunho lógico; se trata, antes, de uma ordem fragmentária e insólita cujo objetivo consistiria no desenvolvimento das "faculdades visionárias". Na verdade, cada texto é uma face desta figura poliédrica cujo vislumbre só pode ser dado na entrevisão dos espaços de corte, na tangência gerada por este mesmo espaço, marcado graficamente pelo ponto preto tão presente como forma de separação e ponto de contato.

A escrita enigmática do "Texto Délfico" segue o tom oracular e talvez alucinatório das pitonisas que caíam em transe. Tal como o furor dionísico que as tomavam, o poeta aproxima-se do "É o oráculo o que digo" de Rimbaud, já que sua voz é também a do vidente, que se faz pelo "longo, imenso, sensato, desregramento de todos os sentidos" (RIMBAUD, 2010, p. 145). A escrita délfica é a escrita das faíscas geradas pelas imagens díspares surrealistas, incompreensíveis desde o ponto de vista lógico. A imagem dispara sentidos opostos e conflitantes que terminam de maneira hermética o visionarismo presente em todo o livro.

O texto délfico é um texto de dimensões aéreas, "O oráculo não tem pés" (MENDES, 1995, p. 1046), em que o branco ganha mais lugar, como um avanço do silêncio sobre o discurso, marcando ainda mais o recuo da palavra. Murilo faz uso de um tempo sem tempo e um espaço sem espaço para lançar-nos num território sem bordas nem apoios, o território mítico. Subvertendo o discurso clássico enquanto visão da totalidade, neste sentido, Murilo Mendes é o vanguardista que fragmenta a realidade e a isola. É, nesta perspectiva, que Murilo afirma seu interesse pela desarticulação do discurso clássico.

Contrapondo a música e a poesia, Adorno põe em evidência o combate travado pela poesia contra seu próprio meio, a linguagem. A primeira enquanto "síntese não-conceitual, imagem originária da poesia" (ADORNO, 1973, p. 106), não traria os problemas que o medium do poeta traz, pois a linguagem, "Em sua qualidade conceitual e predicativa, [...] se opõe à expressão subjetiva, nivela - devido à sua universalidade - o fato a ser expresso para 
um previamente já dado e conhecido. É contra isso que os poetas se revoltam" (idem). Na luta de braço com o "já dado", Adorno mostra, através da poética hölderliniana, o esquivamento ao caráter conceitual da linguagem, nem sempre logrado, através da parataxe.

A supressão da coordenação, do link que explicita e guia a relação entre as partes, entendida aqui não só no âmbito da sintaxe, mas também no da organização dos textos, faz com que a colagem seja, por excelência, paratática. A menção constante à Hölderlin em "Texto Délfico", dentro deste contexto, torna-se significativa:

\title{
(Delfos, Hölderlin.)
}

\begin{abstract}
Os trinta anos, de Hölderlin, passados em Tubingue, à mão do carpinteiro, na ode, trancada, no eclipse da laranja, com janelas de ferro-vidro, a medusa portátil, as letras regressivas, o serrote, a plaina; mas era aqui em Delfos, ou na ubíqüe Tubingue; mas era aqui, recordo-me bem, era em Delfos ou Tubingue, que Apolo a Scardelli atava o laço dos sapatos; e o padre do colégio de Niterói taxou-me louco porque eu declarei: - "Delfos é maior que Roma." - "Imaginações aos 16 anos! Fantasias!". Ora, eu já vira de perto a Anfisbena. Não sabia de nada de Hölderlin, mas já sabia e lera muitas letras sobre Delfos.

De resto em Niterói também existia o mar, gramáticas, dicionários, mulheres, mulheres mínimas, mulheres máximas, fome, sede, o horizonte, nuvem, estrela, queijo, azeitona, cabra, mel, liras, ainda que dissonantes, trilenas, árvores antromorfas, colinas, fogo, colunas, ainda que falsas, homens e mulheres bicando-se afetuosamente, sísifos menores a rolar pedras divertidos, papagaios de seda à moda das águias, tantos tântalos, tantos, papoulas de Proserpina, fechaduras de cara fechada, no monteparnasso próximo levanta-se de Raimundo a Ode; um livro de Platão ao alcance da mão... (MENDES, 1995, p. 1039).
\end{abstract}

A citação traz a presença de Hölderlin não só pela evocação de seu nome e por sua vinculação à Grécia, mas, sobretudo, pela utilização paratática. A enumeração, uma das formas da parataxe, compõe um texto de espaço e tempo simultâneo. Murilo faz de suas memórias em Niterói um compósito grego de Delfos e Tubingue, colando as palavras como as fotografias que quando menino colava em um caderno. ${ }^{1}$ A mesma tendência é salientada por Adorno na poética de Hölderlin:

Confundir épocas, ligar coisas afastadas e isoladas; o princípio, oposto ao discursivo, de tais associações, lembra o alinhamento de membros gramaticais. Ambas as coisas a poesia arrancou da zona de loucura na qual a fuga dos pensamentos cresce igualmente com a disposição de muitos esquizofrênicos que consideram toda coisa real como sinal de uma coisa escondida, carregando-a de significado (ADORNO, 1973, p. 108).

\footnotetext{
1 “Ainda menino eu já colava pedaços da Europa e da Ásia em grandes cadernos. Eram fotografias de quadros e estátuas, cidades, lugares, monumentos, homens e mulheres ilustres, meu primeiro contato com um futuro universo de surpresas. Colava também fotografias de estrelas e planetas, de um e outro animal, e muitas plantas" (MENDES, 1995, p. 973).
} 
A capacidade da parataxe em admitir a coexistência de tempos e espaços distintos e a coordenação do real e do irreal, já não em relação hierárquica, apontam em cheio às estratégias da colagem surrealista. Nesta a inversão da ordem lógica do tempo e do espaço obedece à resistência à admissão do sentido dado, fazendo com que seu principal operador poético seja o deslocamento, como tentamos mostrar anteriormente. Aqui, entretanto, a batalha se radicaliza, pois a escrita poética lança-se contra seu próprio corpo, a linguagem.

O oráculo délfico será o campo de exploração máxima da tentativa de recuo ao sentido pela preponderância do enigma. Nesta perspectiva, atuam no texto não só a constância da parataxe como recurso sintático de escrita, mas também a paranomásia, o trocadilho motivado por semelhanças fonéticas que deixa, por vezes, o texto aparentemente à revelia do som, como se sua própria substância musical estivesse revelada: "O cérebro do cérbero, caos latindo." (MENDES, 1995, p. 1443), "De Eléeia a flechadéia a pura semidéia a flechadéia..." (MENDES, ibidem, p. 146).

Num texto que quer esquivar-se ao aprisionamento do sentido, a imagem do vôo dá força não só à potência da liberdade - "Não se habituando ao novo modelo de vento, aquele pássaro resolve emigrar" (MENDES, ibidem, p. 1047) -, mas também à da fuga da palavra do que ela mesma contém, o tropos, a figura do pensamento. Aqui o sentido de Átropos se enriquece, já que a negação da figura do pensamento, da matéria conceitual da linguagem, desponta de quando em quando no texto. O corte de Átropos, empregado em todos os níveis textuais, acaba por atingir a própria palavra, incidindo contra sua síntese formadora. A crítica ao classicismo, sua desarticulação, acha-se atrapalhada ali mesmo onde ela se faz, na linguagem. Como escapar ao logos se a matéria mesma do poeta, a linguagem, não pode desvencilhá-lo? As palavras, "ermas de melodia e conceito", atrapam aquele que lhe empunha a tesourada final, o corte mais tenso e ambicioso: o da palavra mesma.

Neste sentido, o poeta volta seu olhar ao tempo original da linguagem: "(Vico) Primeiros tempos do mundo. O silêncio desdorme, gera filhos explosivos do silêncio, a metáfora, a onomatopéia" (MENDES, ibidem, p. 1035). Segundo Bosi, Vico "foi o pensador que viu de maneira dinâmica não só as diferenças entre modos de se enfrentarem palavra e realidade, mas, e sobretudo, o seu tenso convívio" (BOSI, 1985, p. 7). Para Vico há três fases da linguagem humana: a primeira, divina, seria a fase mimética na qual o gestual e o silêncio prevaleceriam, em que o logos não substitui o referente. A segunda fase, a heróica, seria analógica, em que a relação da linguagem com o referente ainda não estaria mediada por uma 
rede de categorias convencionais. A terceira, a humana, é a fase racional de "universais lógicos", "quase toda articulada" (BOSI, ibidem, p. 8), em que conceito e palavra não se distinguem.

Como Vico, Pasolini também identifica um momento linguístico gestual, que se afina a proposta da linguagem primeira de Vico. Para Pasolini, a língua oral seria um "continuum estático", como a natureza, fora da evolução histórica. É, este momento, "momento de nossa comunicação oral que é, por conseguinte, puramente natural" (PASOLINI, 1982, p. 167), que se relacionaria com uma língua de ação, livre do logos. Esta concepção linguística também é expressa na escolha de Pasolini pelo friulano como língua de seus primeiros poemas. Este dialeto ininteligível para a maioria dos italianos seria, para ele, "um falar mais puro e mais próximo do momento em que Adão teria pronunciado suas primeiras palavras" (PASOLINI Apud: LAHUD, 1993, p. 59). Voltamos, assim, a perspectiva adâmica da linguagem, tão importante para o pensamento de Pasolini tanto na literatura como no cinema. O estudo do cinema está, assim, indissoluvelmente ligado a sua potência enquanto linguagem “descontaminada", Pasolini deseja fazer uma

\footnotetext{
semiologia da linguagem de ação ou tout court. Quer dizer: alargar horizonte da semiologia e da linguística a ponto de a idéia nos fazer perder a cabeça, ou fazer sorrir de ironia os que se encontram mais familiarizados com o trabalho destas disciplinas - como é justo, de resto, que suceda. Já afirmei no início desta investigação linguística do cinema que ela me importa, não tanto em si própria, como pelas implicações filosóficas que implica [...]. (PASOLINI, idem).
}

São justamente tais implicações filosóficas que nos interessam e mostram que o espectro de atuação de sua teoria nos permite a leitura de um olho-câmera. Trata-se aqui de entender os limites da linguagem verbal enquanto linguagem conceitual e em que medida se propõe uma estética que tensiona os limites da racionalidade ocidental, forjando uma língua que questiona o sentido, que busca o "impensado", como nos fala Deleuze. O olho-câmera de Murilo Mendes, entretanto, não reproduz a linguagem de ação, mas se alça na utopia de articulá-la, ciente de sua impossibilidade. A palavra é este espaço de conflito, espaço que corteja com uma oralidade que parece autonomizar-se para depois jogar com sua própria residência no logos.

Para Artaud, "El primer grado del pensamiento cinematográfico parece que reside en la utilización de los objetos y de las formas existentes, a las cuales se puede dotar de toda expresión, porque las disposiciones de la naturaleza son profundas y verdaderamente infinitas" (ARTAUD, 1973, p. 9). Voltamos aqui não só à idéia de que o cinema não possui 
uma linguagem pré-determinada conceitualmente, tal como defende Pasolini, mas também a idéia de que esta é uma linguagem "natural", linguagem das coisas, linguagem de ação.

A relação entre linguagem não-conceitual e linguagem natural parece saltar à vista. Através do cinema se exibe toda uma articulação dos objetos, das formas e de um mundo que prescinde do racional. É este mundo imanente que se mantém como uma utopia de uma linguagem de tipo "onírico", como se esta realidade das coisas fosse realmente descoberta com o advento do cinema.

A poesia, a partir deste mesmo impulso, aparece em "Texto Délfico" como desejo de recuperação da palavra "em liberdade" de sua conformação conceitual, tal como o ensaio de volta a uma linguagem perdida na qual as palavras ainda não se viam enredadas na teia do logos. Voltar o olhar a este estágio primeiro da linguagem funciona aqui como uma outra face da mesma crítica constante ao saber racional científico que percorre todo o livro e que constitui um olho-câmera. $\mathrm{Na}$ poesia a perspectiva analógica da linguagem serve de instrumento de resistência à submissão ao poder soberano do logos. Segundo Bosi,

\begin{abstract}
O discurso prosaico e, em especial, os discursos científicos e apofânticos, descartam-se, por princípio, das semelhanças sonoras e desconfiam das virtudes simpáticas ou analógicas do signo: a sua moral é a da nua e sóbria exposição dos conceitos. O discurso poético, embora não consiga reimergir-se de todo nas águas do imaginário (pois seria tarefa do Sísifo livrar os signos do peso dos significados com que os grava continuamente a vida em sociedade), joga, o quanto pode, com os processos da "lógica poética", isto é, com as figuras sonoras e sintáticas e semânticas, subsistindo como algo obscuro, objeto surpreendente e estranho nos céus sempre mais aclarados pelas luzes de uma paidéia científica ou ideológica (BOSI, 1977, p. 171).
\end{abstract}

A recuperação do universo grego em Murilo não se direciona aqui à Grécia do pensamento científico e racional, mas a um tempo anterior, à Grécia do oráculo de Delfos, ali onde o mito reina. O próprio oráculo muriliano aborda esta passagem: "O agouro, agora na ágora, agrega os agressores" (MENDES, 1995, p. 1044), “As rodas da opinião nos redemoinhos da ágora" (MENDES, ibidem, p. 1045), fazem referência à figura do filósofo que no espaço público, a ágora, agrega a opinião, fazendo com que, assim, nasça o pensamento racional. Murilo, paradoxalmente, articula, através da paranomásia, um discurso musical, "síntese não conceitual", para indicar a ascensão do pensamento racional em detrimento ao pensamento mítico.

Delfos é, então, o palco da "passagem dialética fundamental da cultura grega: da dúvida abstrata à certeza pessoal do pesquisador" (MENDES, ibidem, p. 1057). Dentro deste contexto, Murilo tenta instalar-se em um escorregadio terreno, o do mito como resistência à 
lógica: "Os inimigos do mito não têm força para criá-los ou recriá-los. Julgam que os mitos acham-se superados pela realidade; quando eles são a própria figura da realidade" (MENDES, ibidem, p.1038). Entre a Grécia berço da filosofia e do pensamento racional e a Grécia mítica, Murilo privilegia a segunda:

(...) talvez acima de tudo, a Grécia possui uma força inesgotável: sua mitologia, que constitui ao mesmo tempo sistema cosmogônico, transposição figurada de fatos reais, reservatório sempre renovado de arquétipos e símbolos. (...) Infelizmente hoje se dá bem pouco desafogo ao lado mítico do homem: este não pode mais criar mitos. (...) A razão, se superestimada, tem isto de comum com o absolutismo político: sob seu domínio individual a vida se empobrece (grifo é meu, MENDES, ibidem, p. 1054).

A afirmação do mito a contrapelo da supremacia do racional pode dirigir-se àquela preocupação anteriormente destacada, a da desarticulação do clássico. Esta proposta, entretanto, no momento mesmo em que tenta cumprir-se se vê numa emboscada: É possível a desarticulação do discurso lógico-racional do clássico através da linguagem em si conceitual?

A precedência do mito em relação ao logos aparece tensionada pelo próprio pendor construtivista que Murilo aciona na configuração do espaço oracular. A tensão aparece aqui, pois o poeta, ao mesmo tempo em que se afigura como vidente, nos aponta ao comando da caótica revelação poética através da figura do cocheiro de Delfos: "O auriga inicia-se ao relâmpago" e da organização desta mesma revelação: "O arquiteto ilumina o relâmpago" (MENDES, ibidem, p. 1036).

A poesia como lugar de crítica do conceitual, comentada anteriormente por Bosi, é retomada por Pasolini em sua defesa de um "cinema de poesia". A linguagem do cinema de poesia "pode ser parábola, mas nunca expressão conceptual direta. E eis assim um modo de afirmar a qualidade artística do cinema: a sua violência expressiva, o seu onírico ser físico (grifo é meu, PASOLINI, 1982, p. 141). Assim como Pasolini, Artaud nos chama a atenção para como o caráter imediato do cinema nos ajuda a aceder a esta "fala anterior às palavras", a a-gramaticalidade a que se refere Pasolini.

A "concreção objetal do cinema", sua linguagem das coisas, é retomada aqui com o objetivo de entender como funciona a crítica racionalista da arte dentro da literatura e sua simultânea defesa do aspecto não conceitual da linguagem verbal. Este "primeiro grau" do cinema, como o denomina Artaud, seria justamente o aspecto que the daria livre acesso a qualquer expressão, uma espécie de grau zero da linguagem, ali onde ela pode tomar qualquer feição, sem a "contaminação" presente na linguagem verbal, dada pelo uso e pela história. É por esta mesma via que Kracauer elogia o cinema: "the eye of the camera gives us that 
extraordinary thing: the world disenfected of consciouness" (KRACAUER, 1997, p.286). A possibilidade de um mundo livre da consciência é em Kracauer a base de uma utopia de redenção do próprio real através do cinema:

We literally redeem this world from its dormant state, its state of virtual nonexistence, by endeavoring to experience it to through the camera. And we are free to experience it because we are fragmentized. The cinema can be defined as a medium particularly equipped to promote the redemption of physical reality. Its imagery permits us, for the firts time, to take away with us the objects and occurences that comprise the flow of material life. (KRACAUER, 1997, p. 300).

É interessante pensar a relação entre violência, a intensidade desta linguagem, marcada por Pasolini, e a utópica pretensão de articular uma linguagem que possa apreender a realidade e redimí-lo, tal como nos indica Kracauer: "The essential material of 'aesthetic apprehension' is the physical world, including all that it may suggest to us. We cannot hope to embrace reality unless we penetrate its lowest layers" (idem). Outra vez, é patente a idéia de submersão, penetração, na realidade como caminho de apreensão estética. Esta sede de real canaliza uma caminho descendente, de aproximação do pequeno, do objetal, do mínimo. A aproximação à materialidade sem intermediações do cinema é capaz de gerar uma estética que encontra nessa mesma materialidade a invisibilidade do real, sua virtualidade encantatória, bruxa. Também fica explícita a relação estreita entre redenção do mundo material e nosso poder de fragmentá-lo, de cortar seu fluxo, essencial para a relação entre literatura e cinema que aqui se tenta estabelecer.

Concluindo, trata-se, antes de mais nada, de atuar sobre o tempo e o espaço de uma outra maneira, alternativa às coordenadas cartesianas, um tempo e um espaço simultâneo, sem hierarquias, um tempo "cheio", um espaço saturado. Estamos frente a uma linguagem na qual prevalece o descontínuo sobre o contínuo. Murilo Mendes, ao declarar a posse de um olhocâmera, aponta para este anseio de uma linguagem que, afirmando sua extrema atenção aos objetos, à matéria, é, ao mesmo tempo, onírica. Uma vez que: "Tanto a mímica como a realidade bruta como os sonhos e os mecanismos da memória, são factos quase pré-humanos ou nos limites do humano: são, em todo o caso, pré-gramaticais e absolutamente prémorfológicos" (PASOLINI, 1982, p. 138). As reflexões em torno do cinema vêm acompanhadas da reflexão sobre a própria linguagem e os limites da palavra. A inflexão "cinematográfica" da escrita muriliana pode ser entendida como parte deste processo de crítica do conceitual e da racionalidade que se leva a cabo na poesia, mas que se utiliza de meios que podemos reconhecer como próprios do cinema ou, pelo menos, de uma certa 
perspectiva do cinema, relacionadas aqui com as de Artaud e Pasolini. O pendor utópico destas perspectivas deixa claro aqui que literatura e cinema pretendem articular uma linguagem na qual "concreção objetal" e "qualidade onírica" estejam indissoluvemente ligadas.

\section{Referências}

ADORNO, Theodor. Parataxis. In: ADORNO, Theodor. Notas de Literatura. Tradução de Jorge de Almeida. Rio de Janeiro: Tempo Brasileiro, 1973.

ARTAUD, Antonin. El cine. Tradução de Antonio Eceiza. Madrid: Alianza Editorial, 1973.

DELEUZE, Giles. Cinema 2: A imagem-tempo. Tradução de Eloísa Araújo Ribeiro. São Paulo: Brasiliense, 1990.

KRACAUER, Sigfried. Theory of Film: The Redemption of Physical Reality. Princeton: Princeton University Press, 1997.

LAHUD, Michel. A vida clara. Linguagens e realidade segundo Pasolini. São Paulo/Campinas: Companhia das Letras/ Editora da Unicamp, 1993.

MENDES, Murilo. Carta Geográfica. In: Poesia completa e prosa. Org. Luciana Stegagno Picchio. Rio de Janeiro: Nova Aguilar, 1995.

. Poliedro. In: . Poesia completa e prosa. Org. Luciana Stegagno Picchio. Rio de Janeiro: Nova Aguilar, 1995.

MERQUIOR, J. Guilherme. "Murilo Mendes ou a Poética do Visionário". In Razão do Poema, Rio de Janeiro, Topbook, 1996, pp.69-89.

MOURA, Murilo Marcondes. A poesia como totalidade. São Paulo: Edusp, 1995.

PASOLINI, Pier Paolo. Empirismo hereje. Tradução de Miguel Serras Pereira. Lisboa: Assírio \& Alvim, 1982.

RIMBAUD, Arthur. Poesia Completa. Rio de Janeiro: Topbooks, 2010.

[Recebido em dezembro de 2011 e aceito para publicação em junho de 2012]

\section{The word impossible to rest: Pasolini and Murilo Mendes' camera-eye}

Abstract: More than a theory of language, the filmaker Pier Paolo Pasolini gave us a theory of the language and its relation to the reality. The cinema appears as a trigger of a philosophical investigation of the possibilities of verbal language in the crossroads between his historicity and the poetical desire to reveal new meaning, or more than that, the struggle 
with the nonexistence of meaning. Establishing ties between Pasolini's theory of cinema and the poetics of Murilo Mendes we seek to think about the poetic of dispossession of meaning through the work of cutting and subtraction concepts direct at the word. Pasolini's proposals theorizes about the cinema, but it's above all a theory of language, a comparison between the possibilities of th verbal and the visual. This theory helps gain a different perspective of Murilo Mendes poetic work, interested in the poetry that is activated through the eye of a camera, an eye capable of uncovering the essentials of the word in a process of subtraction that seeks the permanent displacement of the meaning, the word impossible to rest.

Keywords: Murilo Mendes. Pier Paolo Pasolini. Cinema. Collage.

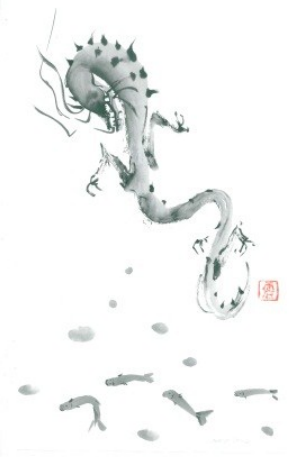

